\title{
Size Reduction of A Microstrip Antenna using Loading Circuit Method for UHF Band
}

\author{
Budi Aswoyo*), Akuwan Saleh"), Arifin") \\ Departmen Teknik Elektro, \\ Politeknik Elektronika Negeri Surabaya, \\ Indonesia \\ budias@pens.ac.id; akuwan@pens.c.id; arifin@pens.ac.id
}

\begin{abstract}
This paper presents a process and result of reduction of the dimensions of microstrip square antenna shorting pins or loading circuit inserted to the antenna comparing to the conventional one. The slits applied to the antenna to generate the circular polarization properties of the antenna. This antenna is called as a Loading Circuit Microstrip Slit (an LCMS) antenna. The antenna is designed to work at a frequency of $435.9 \mathrm{MHz}$. This frequency is a part of UHF band of nano-satellite operation. From the simulation results, by adding a loading circuit of chip resistor $1 \mathrm{Ohm}$ instead of the shorting pin, the overall size of an LCMS antenna will be reduced and the bandwidth of antenna becomes wider. For frequency of $435.9 \mathrm{MHz}$, the return loss of antenna is $-21.445 \mathrm{~dB}$, the bandwidth is $44.13 \mathrm{MHz}$, axial ratio is $2.9 \mathrm{~dB}$, and the total size reduction of an LCMS antenna is equal to $338.46 \%$.
\end{abstract}

Keywords—microstrip antenna; loading circuit; chip resistor

\section{INTRODUCTION}

As is known, nano-satellite is made with a compact size and small with a weight smaller than $10 \mathrm{~kg}$. In the application, an antenna that will be operated in a nano-satellite system in UHF (Ultra High Frequency) band, should be considered the shape and size, because generally bump and size of microstrip antenna in this band is relatively large. Typically, the size of the microstrip antenna will have a length of antenna size should be about half the wavelength in the medium of low permitivity dielectric substrate [1]. To overcome the relatively large size of the antenna, a special method is needed to reduce it.

To reduce the size of a relatively large microstrip antenna when it is analogous to the UHF Band, there are several methods that have been developed, and that is by connecting the ground plane and the patch, also known as the shorting circuit or pin shorting method. This method is widely used because the resonance frequency can be achieved by patch size about half the size of conventional microstrip antenna [1]. Theoretically, a microstrip antenna constructed by a shortcircuit zero-potential field of a plain microstrip antenna will produce the dominant mode. Short circuits are practical and simple like this, much easier than wrapping a copper strip around the edge of the antenna. However, the main problem of the method is that the antenna will have a relatively narrow bandwidth. Therefore, to increase the antenna bandwidth, it is necessary to manipulate a chip resistor in a certain place instead of the shorting pin [1].

In this paper, a Loading Circuit Microstrip Slit (LCMS) antenna is made with patches and use a $1 \mathrm{Ohm}$ chip resistor placed in the right position instead of shorting pin. To get a circular polarization, in the middle there are four gaps in the patch with a certain length and width. Finally, by integrating the coaxial coaxial probe, the resulting microstrip antenna has small size and circular polarization characteristic.

\section{RELATED WORK}

There are several research results related to rectangular microstrip antenna design to reduce the dimensions of antennas large enough to operate at low frequencies, and some work on reducing the size of microstrip antennas. Waterhouse has been presenting the use of shorting circuit methods and adding chip resistors instead of shorting pins with different patches. Another method has also been developed by Porath which is investigating the use of shorting posts. Akhwan S, Budi $\mathrm{A}[1]$ has been presenting the investigation design of microstrip antenna using loading circuit by, but they didn't fabricate this antennas yet.

\section{ANTENA DESIGN AND RESULTS}

In this paper, there are three stages in the LCMS antenna occupancy. The first is a conventional square microstrip antenna, the second is a microstrip antenna with a shorting circuit, and the third is an LCMS antenna. The conventional microstrip antenna is designed as a comparison of dimensional reduction resulting in an LCMS antenna.

\section{A. Conventional Square Microstrip Antenna}

The primilinary design of a conventional square microstrip antenna is shown in Fig.1. The antenna is designed to operate at a frequency of 435.9 MHz. The dimensions of the patch and the substrate are $\mathrm{Wp} \times \mathrm{Lp}$ and $\mathrm{Wg} \times \mathrm{Lg}$, respectively. Where $\mathrm{Wp}$ is the length of patch, Lp is the width of patch, Wg is the length of substrat, and $\mathrm{Lg}$ is the width of substrat. The position of the antenna feeder point coordinate at $\mathrm{P}(\mathrm{x}, \mathrm{y})$. Substrate used as antenna material is FR-4 with dielectric 
constant $(\varepsilon r=4.7, \tan \delta=0.02)$ and thickness $1.6 \mathrm{~mm}$. While the material of antenna, both patch and ground use copper. With a note, the patch is located on the top of the dielectric substrate, while the ground is located at the bottom of the substrate.

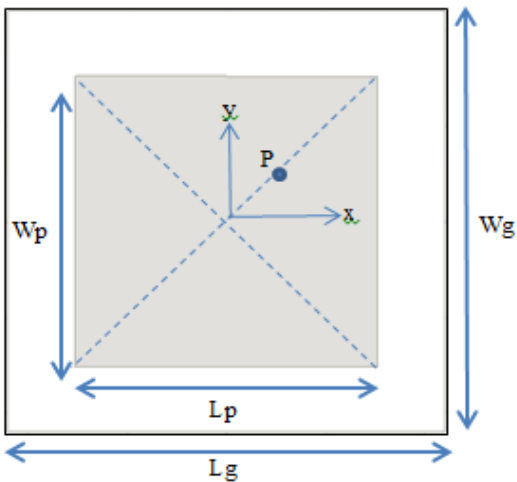

Fig.1. Preliminary design of a conventional square microstrip antenna

The calculation of the antenna size,

$$
\begin{aligned}
& W=\frac{c}{2 f 0 \sqrt{\frac{\varepsilon_{r}+1}{2}}}=\frac{3.10^{8}}{2.435 \times 10^{6} \sqrt{\frac{4.7+1}{2}}}=20.38 \mathrm{~mm} \\
& \varepsilon_{\text {reff }}=\frac{\left(\varepsilon_{r}+1\right)}{2}+\frac{\left(\varepsilon_{r}-1\right)}{2}\left(\frac{1}{\sqrt{1+12 \frac{h}{w}}}\right) \\
& =\frac{(4.7+1)}{2}+\frac{(4.7-1)}{2}\left(\frac{1}{\sqrt{1+12 \frac{0.16}{20.38}}}\right) \\
& =4.168 \text {. } \\
& \Delta L p=0.412 h \frac{\left(\varepsilon_{\text {reff }}+0.3\right)\left(\frac{w}{h}+0.264\right)}{\left(\varepsilon_{\text {reff }}-0.258\right)\left(\frac{w}{h}+0.8\right)} \\
& =0.412 \times 0.16 \frac{(4.618+0.3)\left(\frac{0}{0.16}+0.264\right)}{(4.618-0.258)\left(\frac{0}{0.16}+0.8\right)} \\
& =7.6 \mathrm{~mm} \text {. } \\
& \mathrm{Lp}_{\text {eff }}=\frac{\mathrm{c}}{2 \mathrm{f}_{0} \sqrt{\varepsilon_{\text {reff }}}} \\
& =\frac{3.10^{8}}{2 \times 435.9 \times 10^{6} \sqrt{4.618}}=160.13 \mathrm{~mm} \\
& L p=L p_{\text {eff }}-2 \Delta L p \\
& =160.13-2 \times 7.6=152.53 \mathrm{~mm} \\
& \mathrm{Lp}=\mathrm{Wp}=152.53 \mathrm{~mm} \text {. }
\end{aligned}
$$

TABLE I briefly presents the summary simulation design result of a conventional square microstrip antenna and Fig. 2 shows the size of the antenna with patch and ground dimensions. This square shaped antenna with a ground dimension is $152.53 \mathrm{~mm} \times 152.53 \mathrm{~mm}$, while the patch dimension is $220.00 \mathrm{~mm} \times 220.00 \mathrm{~mm}$. The coaxial probe is placed on the diagonal line of the patch at the coordinate position $(20.00 \mathrm{~mm}, 0)$.

TABLE I. Summary Design Result of a CONVENTIONAL SQUARE MICROSTRIP ANTENNA

\begin{tabular}{|c|c|c|}
\hline No: & Dimension/Position: & Units/Coordinate: \\
\hline 1. & Length of patch (Lp) & $152.53 \mathrm{~mm}$ \\
\hline 2. & Width of patch (Wp) & $152.53 \mathrm{~mm}$ \\
\hline 3. & Length of substrat $(\mathrm{Lg})$ & $220.00 \mathrm{~mm}$ \\
\hline 4. & Width of substrat $(\mathrm{Lg})$ & $220.00 \mathrm{~mm}$ \\
\hline 5. & $\begin{array}{c}\text { Position of coaxial probe } \\
(\mathrm{x}, \mathrm{y})\end{array}$ & $(20.00,20.00) \mathrm{mm}$ \\
\hline
\end{tabular}

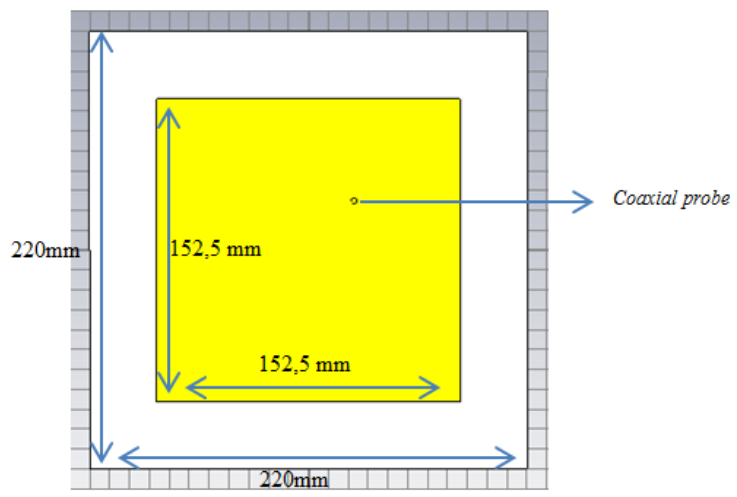

(a)

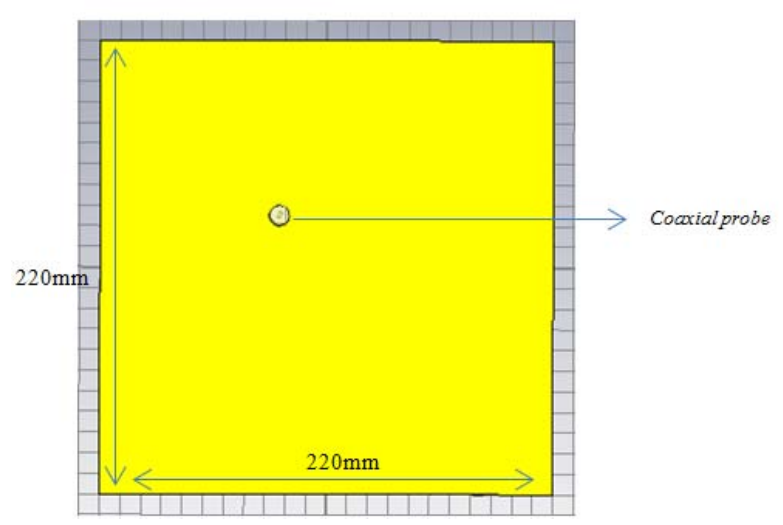

(b)

Fig.2. Design result of a conventional square microstrip antenna (a)front view: (b) rear view

(a)

Figure 3 is shown the S11 or return loss parameter simulation result of conventional microstrip antenna, and Fig. 4 shows the prototype of a conventional square microstrip antenna.

The $\mathrm{S} 11$ center of frequency $435.9 \mathrm{MHz}$ is $-21.486 \mathrm{~dB}$, and the bandwidth of antenna with return loss $-10 \mathrm{~dB}$ simulation results is $4.02 \mathrm{MHz}$ and VSWR is 1.2 . 


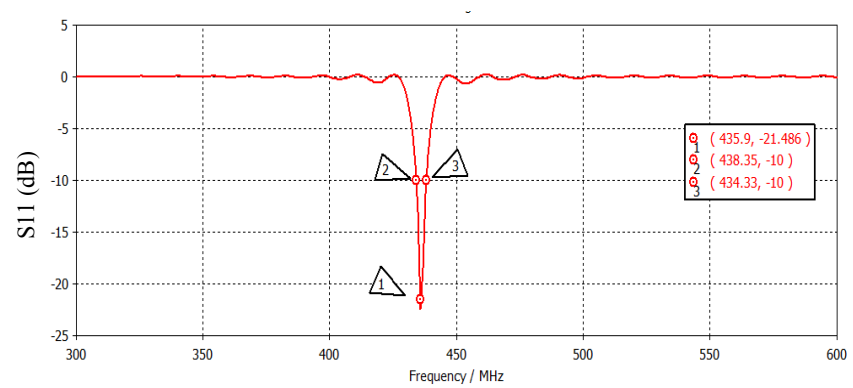

Fig.3. S11 parameters of a conventional square microstrip antenna

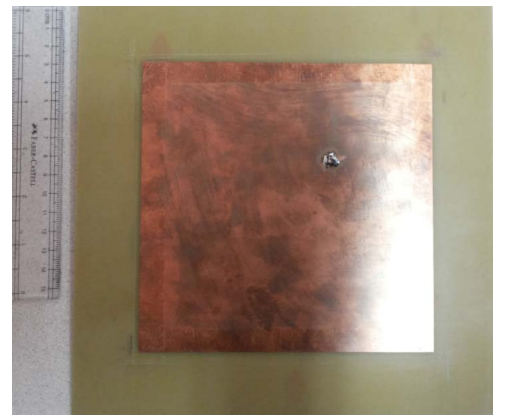

(a)

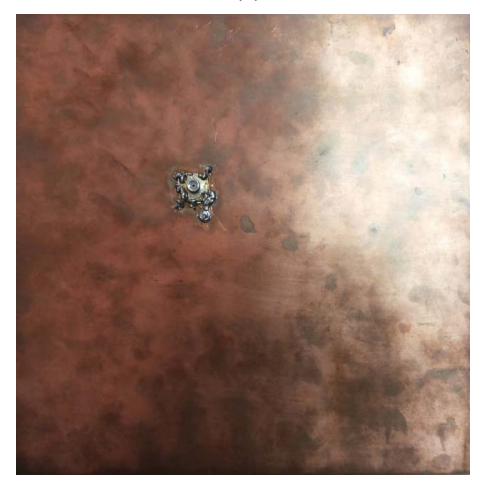

(b)

Fig. 4. Prototype of a conventional square microstrip antenna; (a) patch view: (b) ground view

\section{B. A Microstrip Antenna with Shorting Circuit}

The second stage is designing a microstrip antenna with shorting circuit. The antenna is also designed at a frequency of 435.9 MHz, and with the substrate used is FR-4. To reduce the dimensions of the antenna, it is necessary to use the technique of shorting circuit.

There is no specific formula to calculate the dimensions of the microstrip antenna with shorting circuit [3]. The working principle of this method is that there is an element shorting plate that connects the side edges of the patch and the ground or a shorting pin is a pin that is placed at a specific position along the $\mathrm{x}$ axis of the patch. This pin connects between the patch and the ground. Shorting pin is placed near the coaxial probe will form a transmission line and produce a capacitive component of the input impedance of the patch will eliminate inductance and coaxial probe. When the location of the shorting pin is shifted away from the coaxial probe, the capacitance will decrease and the shorting pin turns into an inductive component to produce $1 / 4 \lambda$ antenna (quarter wave patch).

The simulated design results and the dimensions of the square microstrip antenna with two shorting pins with a diameter of $1 \mathrm{~mm}$ are shown in Fig.5. From the design result, the dimension of patch antenna is $88.50 \mathrm{~mm} \times 88.50 \mathrm{~mm}$, and the dimension of ground is $120.00 \mathrm{~mm} \times 120.00 \mathrm{~mm}$. There are two shorting pins placed in positions $(5.00 \mathrm{~mm}, 0)$ and $(35.00 \mathrm{~mm}, 0)$, as long as the coaxial probe is placed at $(20.00 \mathrm{~mm}, 0)$. The shorting pins position will affect the input impedance generated. These shorting pins are connected the patch and the ground. So the thing to look for is where to place the shorting pin in the appropriate position.

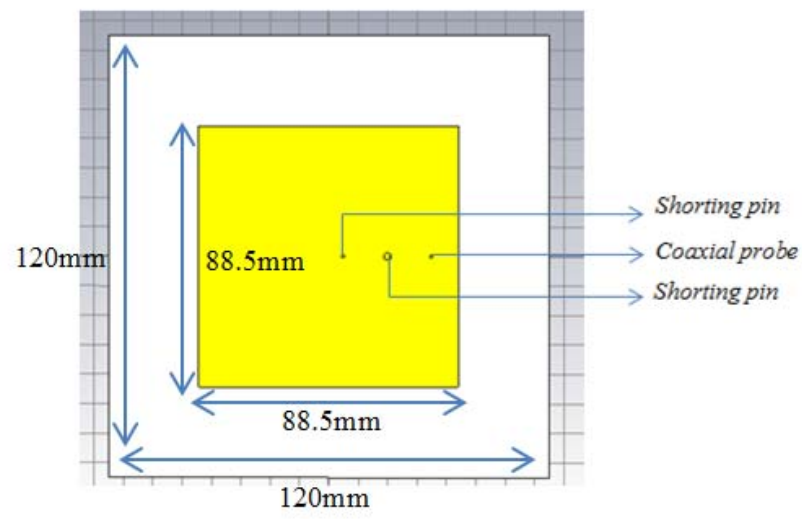

(a)

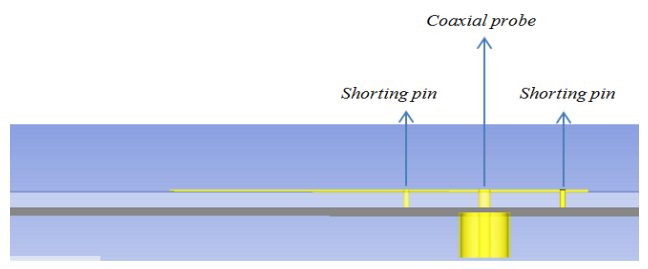

(b)

Fig.5. A square microstrip antenna with shorting circuit/pins (a) Top view (b) Side view

Fig. 6 shows the S11 parameter of a square microstrip antenna with shoring circuits. At the frequency $435.9 \mathrm{MHz}$, the $\mathrm{S} 11$ of simulation result is $-18.296 \mathrm{~dB}$, and the bandwidth is equal to $3.49 \mathrm{MHz}$. In this case, an effort needs to be done to increase the antenna bandwidth.

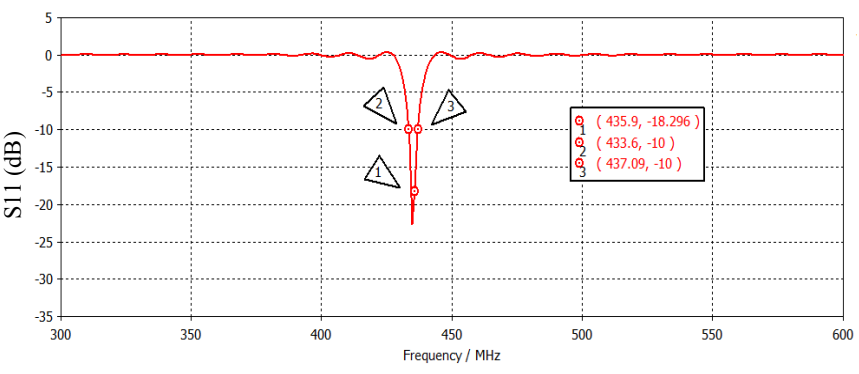

Fig.6. The S11 parameter of a square microstrip antenna with two shoring circuits 


\section{A LoAding Circuit Microstrip Slit (LCMS) ANTENNA}

The priliminary design of an LCMS antenna with resistor chip in Fig.7. This technique is engineered by replacing pin shorting pins in the antenna with a low resistance chip resistor as antenna load. The dimensions of the patch and the ground are $\mathrm{Wp} \times \mathrm{Wp}$ and $\mathrm{Wg} \times \mathrm{Wg}$, respectively. The coaxial probe is placed on the diagonal line of the antenna at position $\mathrm{P}(\mathrm{x}, \mathrm{y})$, and four slits on the four sides of the patch with the same length and width, where the length of each slot is $(y / 2)$ and the width of each slot is (d). In this case, with the same operating frequency $435.9 \mathrm{MHz}$, the required antenna size can be significantly reduced, and the antenna bandwidth can be widened.

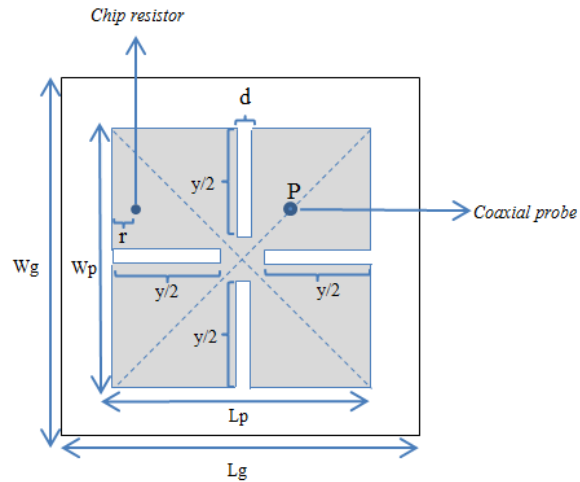

Fig.7. The priliminary design of an LCMS antenna with resistor chip

TABLE II presents a summary of the dimensions or positions of an LCMS antenna design, and Fig. 8 shows the antenna in top and side views. The patch dimension is $42.00 \mathrm{~mm} \times 42.00 \mathrm{~mm}$, and the ground dimension is $65.00 \mathrm{~mm} \times$ $65.00 \mathrm{~mm}$. The coaxial probe of the antenna is at position $(8.25 \mathrm{~mm}, 8.25 \mathrm{~mm})$, and four slits on the four sides of the patch of each slot $(y / 2)$ is $14.50 \mathrm{~mm}$ and the width of each slot (d) is $1.50 \mathrm{~mm}$. The load resistor chip used has a resistance of $1 \mathrm{Ohm}$. This antenna generates the RHCP polarization (righthanded circular polarization).

TABLE II. SUMMARY OF DiMENSION/POSITION OF A LOADNIG

\begin{tabular}{|c|c|c|}
\hline No: & Dimension/Position: & Unit/Coordinate: \\
\hline 1. & Length of patch (Lp) & $42.00 \mathrm{~mm}$ \\
\hline 2. & Width of patch (Wp) & $42.00 \mathrm{~mm}$ \\
\hline 3. & Length of substrat (Lg) & $65.00 \mathrm{~mm}$ \\
\hline 4. & Width of substrat (Wg) & $65.00 \mathrm{~mm}$ \\
\hline 5. & $\begin{array}{c}\text { Position of coaxial probe } \\
(\mathrm{r})(\mathrm{x}, \mathrm{y})\end{array}$ & $(8.25 \mathrm{~mm}, 8.25 \mathrm{~mm})$ \\
\hline 6. & $\begin{array}{c}\text { Length of slit (y/2) } \\
\text { Width of slit (d) }\end{array}$ & $1.50 \mathrm{~mm}$ \\
\hline 7. & $\begin{array}{c}\text { Loading circuit (chip } \\
\text { resistor) (x,y) }\end{array}$ & $(-15.5 \mathrm{~mm}, 8.25 \mathrm{~mm})$ \\
\hline 8. & \multicolumn{2}{c}{} \\
\hline
\end{tabular}

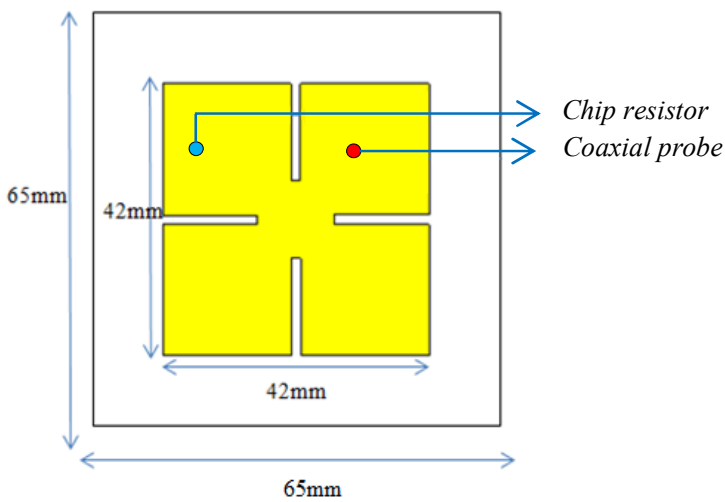

(a)

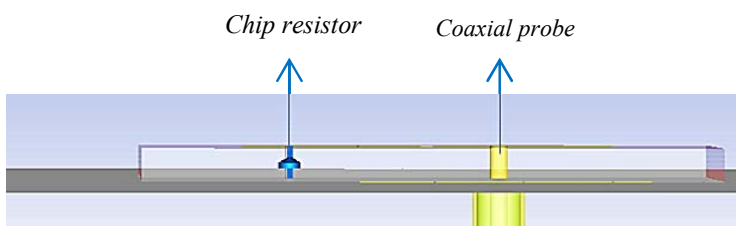

(b)

Fig.8. Design result of an LCMS antenna (a) Top view (b) Side view

Fig.9 shows the S11 or return loss parameter of an LCMS antenna and Fig.10 is prototype of an LCMS antennas has been fabricated on a FR-4 substrat. At frequency of 435.9 $\mathrm{MHz}$, the value of $\mathrm{S} 11$ is $-21.445 \mathrm{~dB}$. The $-10 \mathrm{~dB}$ bandwidth of return loss is $44.13 \mathrm{MHz}$. It is larger than used shorting pins $(4.39 \mathrm{MHz})$. Based on the simulation results, the value of the axial ratio is 1.4 or $2.9 \mathrm{~dB}$ least than $3 \mathrm{~dB}$. Therefore, characteristic of antenna is circular polarization.

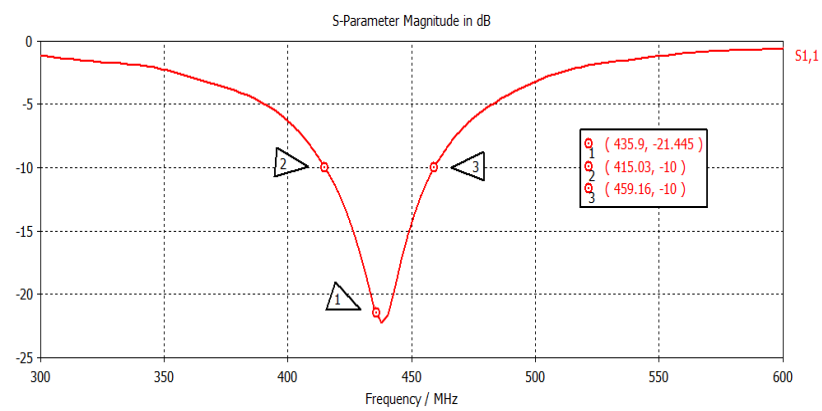

Fig. 9. S11 parameter of an LCMS antenna (result of simulation)

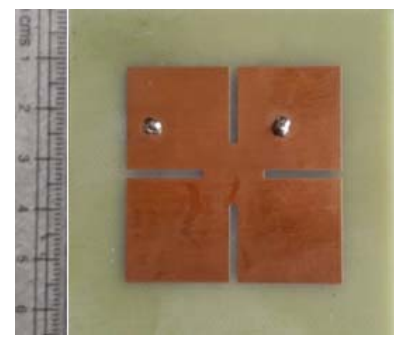

(a)

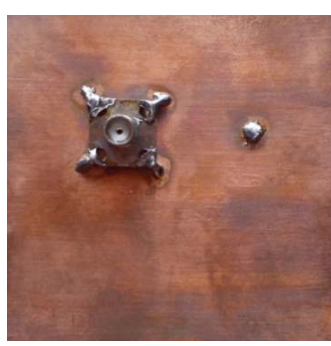

(b)
Fig.10. Prototype of an LCMS antenna with $1 \mathrm{Ohm}$ chip resistor; (a) Top view with ruler (b) Rear view 
TABLE III shows comparison of characteristics of an LCMS antenna and the conventional one. The comparison size is at the frequency $435.9 \mathrm{MHz}$, that is the operated frequency in a nano-satellite system in UHF (Ultra High Frequency) band. The size of dimension of patch and substrat of an conventional square microstrip antenna is $152.53 \mathrm{~mm} \mathrm{x}$ $152.53 \mathrm{~mm}$ and $220.00 \mathrm{~mm} \times 220.00 \mathrm{~mm}$, respectively. The $\mathrm{S} 11$ or return loss is $-21.486 \mathrm{~dB}$ and bandwidth is $4.02 \mathrm{MHz}$, and the polarization is linear. While size of dimension an LCMS is $42.00 \mathrm{~mm} \times 42.00 \mathrm{~mm}$ and $65.00 \mathrm{~mm} \times 65.00 \mathrm{~mm}$, the $\mathrm{S} 11$ or return loss is $-21.445 \mathrm{~dB}$ and bandwidth is $43.13 \mathrm{MHz}$, and the polarization is circular.

Fig.11 shows comparison size of prototype of an LCMS antenna to the conventional one, that is fabricated with same substract (FR-4 substrat). The left side is an LCMS antenna with $1 \mathrm{Ohm}$ chip resistor and the right side is conventional one.

\begin{tabular}{|c|c|c|}
\hline & $\begin{array}{c}\text { Conventional } \\
\text { Square Microstrip } \\
\text { Antenna }\end{array}$ & $\begin{array}{l}\text { Loading Circuit } \\
\text { Microstrip Slit } \\
\text { (LCMS) Antenna } \\
\end{array}$ \\
\hline $\begin{array}{l}\text { Dimension of } \\
\text { patch }\end{array}$ & $\begin{array}{c}152.53 \mathrm{~mm} \mathrm{x} \\
152.53 \mathrm{~mm}\end{array}$ & $\begin{array}{c}42.00 \mathrm{~mm} \mathrm{x} \\
42.00 \mathrm{~mm}\end{array}$ \\
\hline $\begin{array}{c}\text { Dimension of } \\
\text { substrat }\end{array}$ & $\begin{array}{c}220.00 \mathrm{~mm} \mathrm{x} \\
220.00 \mathrm{~mm}\end{array}$ & $\begin{array}{c}65.00 \mathrm{~mm} \mathrm{x} \\
65.00 \mathrm{~mm}\end{array}$ \\
\hline $\begin{array}{c}\text { S11 or return } \\
\text { loss }\end{array}$ & $-21.486 \mathrm{~dB}$ & $-21.445 \mathrm{~dB}$ \\
\hline Bandwidth & $4.02 \mathrm{MHz}$ & $44.13 \mathrm{MHz}$ \\
\hline Polarization & Linear & Circular \\
\hline
\end{tabular}

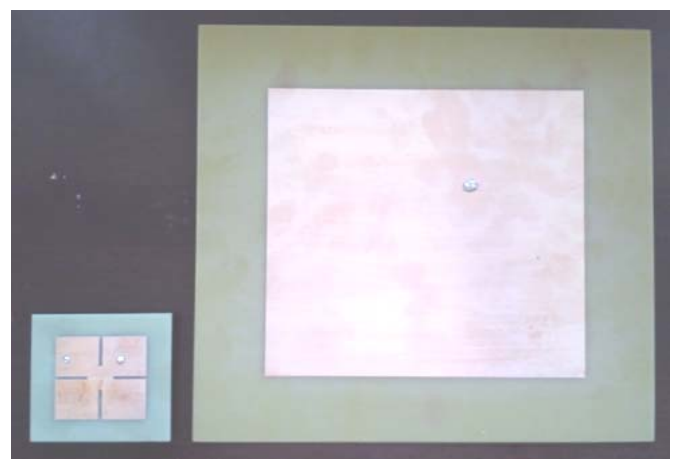

Fig. 11. The comparison size of prototype of an LCMS antenna and the conventional one. The total size reduction is equal to $338.46 \%$

When we compare the dimensions of antenna, the dimension of conventional square microstrip antennas is $220.00 \mathrm{~mm} \times 220.00 \mathrm{~mm}$, while the dimension of an LCMS is $65.00 \mathrm{~mm} \times 65.00 \mathrm{~mm}$, then the total antenna size reduction an LCMS comparing to the conventional one is $338.46 \%$.

\section{CONCLUSION}

Size reduction of a microstrip antenna using a loading circuit using FR4 material has been presented in this paper. This method is combined with the addition of 1 Ohm chip resistor instead of the shorting circuit, in order to widen the antenna bandwidth. In this case, the return loss of antenna is $-21.445 \mathrm{~dB}$, the bandwidth is $43.13 \mathrm{MHz}$. The axial ratio of antenna is $2.9 \mathrm{~dB}$, so the circular polarization has been achieved. The total size reduction of an LCMS antenna with 1 Ohm chip resistor comparing to a conventional square microstrip antenna is equal to $338.46 \%$.

For the future, to get better results it is necessary to try to design and implement microstrip antennas with different materials with FR4, such as duroid or teflon material.

\section{References}

[1] Akuwan Saleh, Budi Aswoyo, "Design Investigation of Microstrip Antenna using Loading Circuit (LC) Method for Amateur Satellite Communication UHF Band," The 2017 International Electronics Symposium on Engineering Technology and Applications (IES-ETA), 26-27 Sept. 2017, p.63-68.

[2] Zaenal Muludi, Budi Aswoyo, "Truncated microstrip square patch array antenna $2 \times 2$ elements with circular polarization for S-band microwave frequency," The 2017 International Electronics Symposium on Engineering Technology and Applications (IES-ETA), 26-27 Sept. 2017. 